\title{
The rectification of an electrical synapse can change the functional output of a pattern- generating circuit
}

\author{
Gabrielle J Gutierrez, Eve Marder \\ From Twenty Second Annual Computational Neuroscience Meeting: CNS*2013 \\ Paris, France. 13-18 July 2013
}

Electrical synapses are known to promote synchrony and speed in neuronal systems. However, other studies have found that electrical synapses can have the opposite effect by desynchronizing network neurons. Although they are mechanistically simple, electrical synapses can have unintuitive effects on neuronal network activity. The present study aims to further our understanding of electrical synapses by exploring their rectification in a neuronal circuit model. Rectification is the asymmetrical passage of current through a gap junction between two neurons and it is often likened to a diode in an electrical circuit. Rectifying electrical synapses have been shown to support specialized functions in several biological preparations [1]. We investigate how rectification affects the functional output of a 5-cell, pattern-generating, model network and its sensitivity to synaptic modulation. The circuit is composed of heterogeneous neurons with different intrinsic oscillation frequencies. Neurons were modeled as Morris-Lecar [2] neurons modified by a hyperpolarization-activated current as in a previous study [3].

We find that circuit output depends on the polarity and placement of the rectifying electrical synapse and the intrinsic properties of the neurons on either side of it (Figure 1). Furthermore, using the parameterscape visualization method [3], we find that rectification can affect the circuit's sensitivity to modulation of synaptic strength including modulation of chemical synapse strength. This

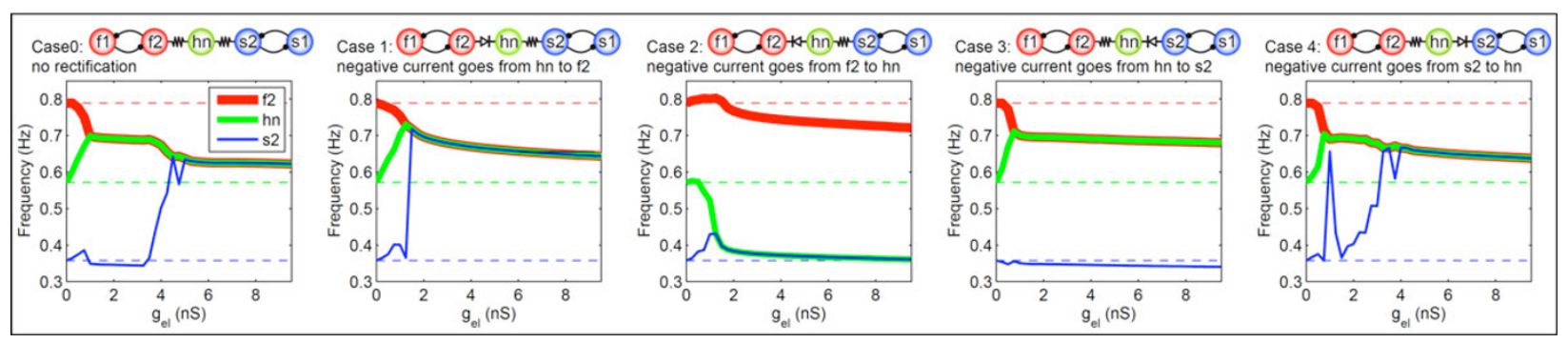

Figure 1 In a 5-cell pattern-generating circuit of heterogeneous neurons, f1 and f2 are intrinsically fast oscillators, s1 and s2 are intrinsically slow oscillators, and the "hub neuron" (hn) which is electrically coupled to both of the rhythm-generating parts of the circuit is an intrinsic oscillator of intermediate frequency (plotted dashed lines represent respective intrinsic frequencies). The 3 electrically coupled neurons synchronize at a common frequency with sufficient coupling strength when electrical synapses are non-rectifying (case 0 ) as well as when the polarity and placement of the rectifying electrical synapse cooperates with the intrinsic neuron properties (cases 1 and 4). When the polarity and placement of the rectifying electrical synapse antagonizes the neuron intrinsic properties, one of the rhythmgenerating parts of the circuit is cut off from the rest of the circuit (cases 2 and 3).

\footnotetext{
* Correspondence: gg99@brandeis.edu

Volen Center for Complex Systems, Brandeis University, Waltham, MA 02454, USA
} 
can have a dramatic effect on the functional output of a pattern-generating circuit. For a multi-functional motor network, it is important to be able to switch between stable network patterns by synaptic neuromodulation. However, our results show that some kinds of electrical synapse rectification can switch off multi-functionality even when there are degenerate synaptic pathways. In conclusion, these results demonstrate how a rectifying electrical synapse has the potential to specialize a neuronal circuit for robust output or for flexibility.

Published: 8 July 2013

\section{References}

1. Rela L, Szczupak L: Gap junctions: Their Importance for the Dynamics of Neural Circuits. Molecular Neurobiology 2004, 30(3):341-357.

2. Morris $\mathrm{C}$, Lecar $\mathrm{H}$ : Voltage oscillations in the barnacle giant muscle fiber. Biophysical Journal 1981, 35(1):193-213.

3. Gutierrez GJ, O'Leary T, Marder E: Multiple mechanisms switch an electrically coupled, synaptically inhibited neuron between competing rhythmic oscillators. Neuron 2013.

doi:10.1186/1471-2202-14-S1-P259

Cite this article as: Gutierrez and Marder: The rectification of an electrical synapse can change the functional output of a patterngenerating circuit. BMC Neuroscience 2013 14(Suppl 1):P259.

Submit your next manuscript to BioMed Central and take full advantage of:

- Convenient online submission

- Thorough peer review

- No space constraints or color figure charges

- Immediate publication on acceptance

- Inclusion in PubMed, CAS, Scopus and Google Scholar

- Research which is freely available for redistribution

Submit your manuscript at www.biomedcentral.com/submit 